\title{
rcites: An R package to access the CITES Speciesplus database
}

\author{
Jonas Geschke ${ }^{1}$, Kevin Cazelles ${ }^{2}$, and Ignasi Bartomeus ${ }^{3}$
}

1 Museum für Naturkunde Berlin - Leibniz Institute for Research on Evolution and Biodiversity, Berlin, Germany 2 Department of Integrative Biology, University Of Guelph, Guelph, Ontario, Canada 3 Estación Biológica de Doñana (EBD-CSIC), Sevilla, Spain

DOI: $10.21105 /$ joss. 01091

\section{Software}

- Review ¿

- Repository ¿

- Archive ca

Submitted: 19 November 2018 Published: 20 November 2018

\section{License}

Authors of papers retain copyright and release the work under a Creative Commons Attribution 4.0 International License (CC-BY).

\section{Introduction}

The conservation of biodiversity is a complex problem strongly tight to political actions. CITES, the Convention on International Trade in Endangered Species of Wild Fauna and Flora, is a multilateral environmental agreement that was established in 1975 (CITES, n.d.) and aims to monitor and regulate the trade of endangered species so that their trade does not threaten the survival of the species in the wild (CITES, n.d.). CITES is one of the eight main international agreements relevant to biodiversity (CBD, n.d.) and constitutes a key tool for conservationists, scientists and policy makers.

\section{The Speciesplus database}

In 2013, the UNEP World Conservation Monitoring Centre (UNEP-WCMC) and the CITES Secretariat initiated a partnership funded by UNEP, the European Commission and the CITES Secretariat. Together, they created Speciesplus (or Species+), a comprehensive database of not only CITES listed species and their regulation status within CITES but also the species' status within the EU legislation and the species' status within the Convention on the Conservation of Migratory Species of Wild Animals (CMS) (UNEP, n.d.a). Speciesplus is publicly available at https://speciesplus.net (UNEP, n.d.b).

\section{The rcites $\mathbf{R}$ package}

With rcites we provide an $\mathrm{R}$ (R Core Team, 2018) client to the Speciesplus/CITES Checklist API, giving access to the Speciesplus database. The ability to query the Speciesplus database directly from one of the most used programming languages for data analyses will improve the efficiency and reproducibility of biodiversity conservation analysis workflows.

We provide functions to:

1. access the Speciesplus taxon concept, and thereafter

2. get a species' legislation status, both from CITES and from the European Union,

3. get a species' country-wise distribution range, as listed in Speciesplus, and

4. get the references on which a Speciesplus listing is based. 
Overall information about rcites and the package vignette can be found at https: //ropensci.github.io/rcites/. The package is available for download from CRAN (stable version; https://cran.r-project.org/package=rcites) and Github (development version; https://github.com/ropensci/rcites).

rcites will support researchers and national authorities in more efficiently dealing with information of endangered species and their legislation status.

Recent publications with data extraction from the Speciesplus database illustrate in what kind of research the package may be of help (Hinsley \& Roberts, 2018; Robinson \& Sinovas, 2018). In the spirit of CITES, research in regard to illegal wildlife trade may be pointed out especially (Ingram et al., 2015; Zhou, 2015; Zhou et al., 2016).

\section{Acknowledgments}

Many thanks to the British Ecological Society for bringing us together during the "Ecology Hackathon: Developing R Packages for Accessing, Synthesizing and Analyzing Ecological Data", part of the BES, GfÖ, NecoV and EEF Joint Annual Meeting 2017 "Ecology Across Borders". Also, thanks to our hackathon group and package reviewers for the fruitful discussions and contributions to the package.

\section{References}

CBD. (n.d.). Biodiversity-related conventions. https://www.cbd.int/brc; Secretariat of the Convention on Biological Diversity, Montreal, Canada.

CITES. (n.d.). What is cites? https://cites.org/eng/disc/what.php; CITES Secretariat, Geneva, Switzerland.

Hinsley, A., \& Roberts, D. L. (2018). The wild origin dilemma. Biological Conservation, 217, 203-206. doi:https://doi.org/10.1016/j.biocon.2017.11.011

Ingram, V., Loo, J., Dawson, I., Vinceti, B., Duminil, J., Muchugi, A., Awono, A., et al. (2015). Perspectives for sustainable prunus africana production and trade. Retrieved from http://hdl.handle.net/10568/71261

R Core Team. (2018). R: A language and environment for statistical computing. Vienna, Austria: R Foundation for Statistical Computing. Retrieved from http://www.R-project. org/

Robinson, J. E., \& Sinovas, P. (2018). Challenges of analyzing the global trade in citeslisted wildlife. Conservation Biology. doi:10.1111/cobi.13095

UNEP. (n.d.a). About species+. https://speciesplus.net/about; UN Environment, Nairobi, Kenya. Compiled by UNEP-WCMC, Cambridge, UK.

UNEP. (n.d.b). The species+ website. https://speciesplus.net; UN Environment, Nairobi, Kenya. Compiled by UNEP-WCMC, Cambridge, UK.

Zhou, Z.-M. (2015). China: Outdated listing puts species at risk. Nature, 525(187). doi:https://doi.org/10.1038/525187a

Zhou, Z.-M., Chris, N., D., B. C., Xiuxiang, M., W., M. D., \& Youbing, Z. (2016). Revised taxonomic binomials jeopardize protective wildlife legislation. Conservation Letters, 9(5), 313-315. doi:10.1111/conl.12289 